\title{
Unikale Inkunabel mit Regionalbezug
}

Der im Sommer 2014 erworbene Teil 3 und 4 des ca. 1473 gedruckten "Breviarium Constantiense" (GW 5315) ergänzt trotz einiger fehlender Seiten in herausragender Weise die Inkunabelsammlung der WLB (Inc.fol.3826a (2)). Teil 1, 2 und 5 dieser weltweit unikalen Inkunabel - ebenfalls in einen Band gebunden - gelangte mit den Bänden der Fürstlich Fürstenbergischen Hofbibliothek Donaueschingen bereits 1994 in den Bestand. Es handelt sich neben den eindeutig datierbaren Inkunabeln aus Speyer (1471) (Inc.qt.13310) bzw. Ulm (1473) (Inc.qt.13737) um einen der frühesten Drucke aus Südwestdeutschland. Dabei wird eine Textura-Type in zwei Schriftgrößen verwendet.

Inhaltlich geht es um den Sommerteil (pars aestivalis) des Breviers der bis 1821 existierenden Diözese Konstanz. Es ist ein liturgisches Buch zur Durchführung des Stundengebetes mit gemeinsamen und regional abweichenden Teilen. Die liturgische Eigenart des jeweiligen Tages ergibt sich aus den Kirchenfesten im Verlauf des Kirchenjahres sowie aus der Zuordnung der Heiligen zu bestimmten Tagen. Regionale Besonderheiten entstehen vor

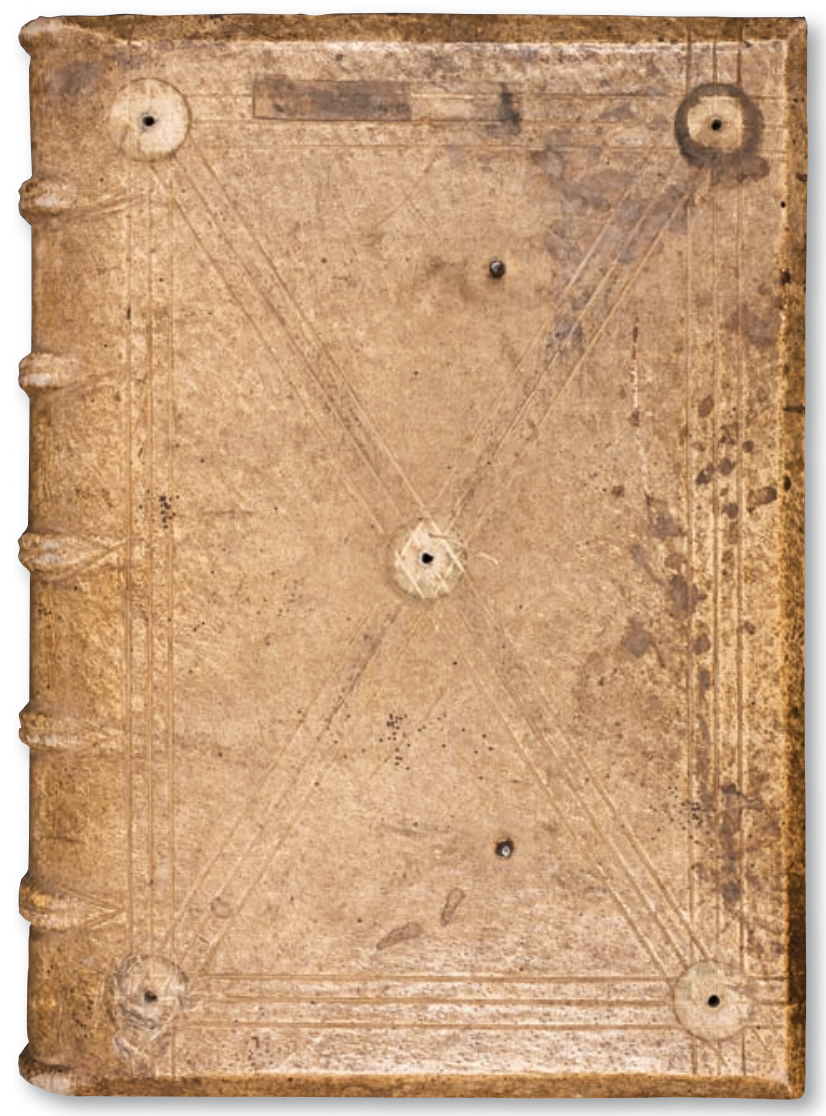

allem durch Berücksichtigung örtlich bedeutsamer Heiliger.

Eigenart des vorliegenden Exemplars aus dem Vorbesitz der Hofbibliothek Sigmaringen sind an mehreren Stellen eingedruckte Lagensignaturen. Sie sind Ausgangspunkt für Paginierung bzw. Kollationierung. Lombarden und Kapitelüberschriften sowie Initialen wurden per Hand mit roter Tinte eingetragen. Die Laufrichtung und Buchstabenform dieser handschriftlichen Ergänzungen weichen vom Exemplar aus Donaueschingen ab. Daher handelt es sich um eine zwar ausgabenspezifische, nicht jedoch exemplarspezifische Ergänzung des bereits vorhandenen Inkunabelbandes.

Bemerkenswert sind die sonst seltenen Langriemenschließen auf dem mit Streicheisenlinien verzierten Schweinslederband sowie der Abklatsch einer Pergamenthandschrift aus den Britischen Inseln auf den Spiegeln. Von den ehemals fünf Metallbeschlägen auf Vorder- und Rückdeckel sind nur noch Spuren erkennbar.

Christian Herrmann

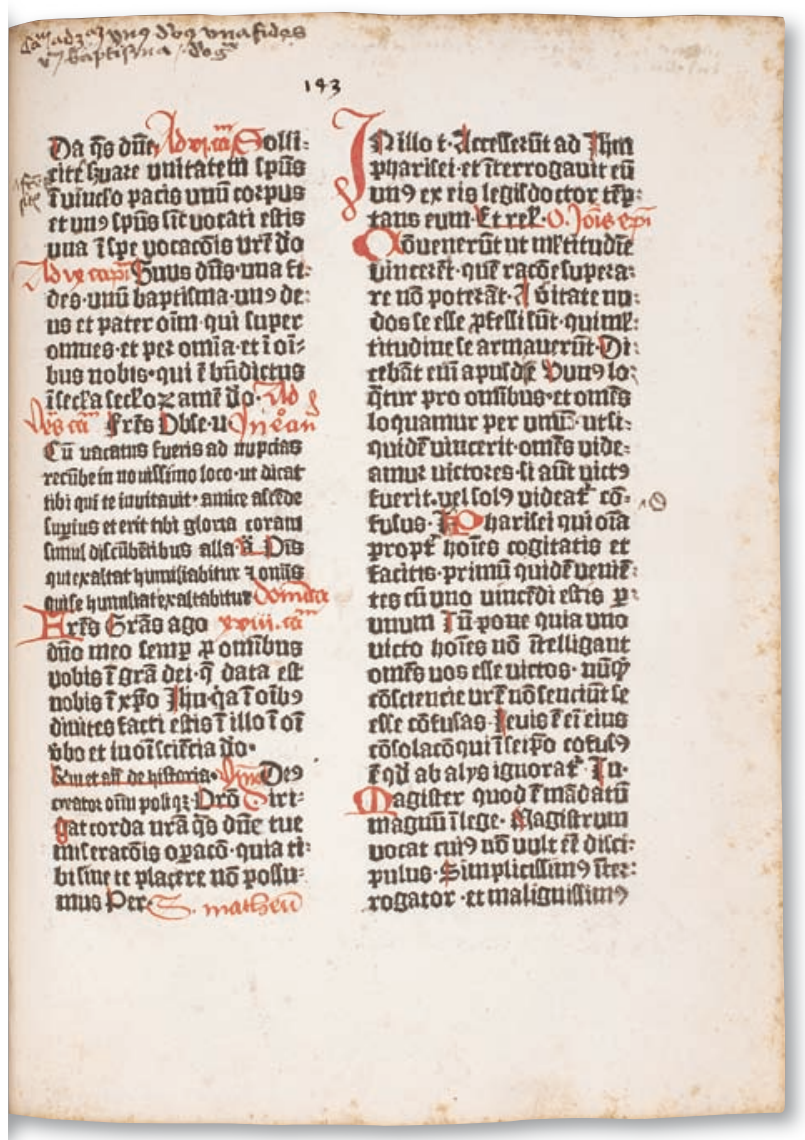

